\title{
Production of urokinase by HT 1080 human kidney cell line
}

\begin{abstract}
Studies were carried out in T-flasks and bioreactor to produce urokinase enzyme using HT 1080 human kidney cell line. While growing the cell line it has been observed that the lag phase is reduced considerably in the bioreactor as compared to T-flask culture. The HT 1080 cell adhesion rate and urokinase production were observed to be the function of serum concentration in the medium. The maximum urokinase activity of 3.1 x 10-4 unit ml-1 was achieved in the bioreactor at around $65 \mathrm{~h}$ of batch culture. Since HT 1080 is an anchorage dependent cell line, therefore, the hydrodynamic effects on the cell line were investigated.
\end{abstract}

Keyword: Bioreactor; HT 1080 human kidney cell line; Hydrodynamic effects; Urokinase 